\title{
Arnebia Indigo Jade Pearl Topical Cream
}

National Cancer Institute

\section{Source}

National Cancer Institute. Arnebia Indigo Jade Pearl Topical Cream. NCI Thesaurus. Code C74013.

A proprietary multiherbal topical cream based on Chinese herbal medicine with potential antineoplastic, antiviral, antibacterial and immunostimulatory activities. Arnebia Indigo Jade Pearl topical cream contains 12 ing redients including 9 herbs infused in sesame oil, with an additional three powdered ing redients and beeswax added to the infused oil to create the salve. The purported mechanism(s) of action is unclear due to the complexity of the herbal mixture. 